\title{
Interaction of Murine Granulocyte-Macrophage Progenitors and Supporting Stroma Involves a Recognition Mechanism with Galactosyl and Mannosyl Specificities
}

\author{
Shin Aizawa and Mehdi Tavassoli \\ Veterans Administration Medical Center and University of Mississippi School of Medicine, Jackson, Mississippi 39216
}

\begin{abstract}
To study the molecular basis of "homing" of granulocyte-macrophage progenitors (CFU-C), we synthesized probes by covalent linking of sugars to bovine serum albumin. Long-term marrow cultures were established in the presence and absence of these probes. In the presence of galactosyl and mannosyl probes, total cell and CFU-C production in the supernate as well as the adherent layer were halted, and cobblestones (representing CFU-C bound to stroma) disappeared. Fucosyl probe and diffusible sugars had no effect on these parameters. These studies suggested membrane lectins with specificity for galactosyl and mannosyl residues may be responsible for the binding of CFU-C to supporting stroma. To determine if CFU-C possesses homing receptors with these specificities, we induced agglutination in marrow cell suspensions with these neoglycoprotein probes. Selective agglutination was observed only by galactosyl and mannosyl probes. The results suggest that CFU-C homing receptors are membrane lectins with specificity for galactosyl and mannosyl residues.
\end{abstract}

\section{Introduction}

Interactions between sugar residues of membrane glycoproteins and receptors capable of specific binding to these residues have recently been implicated in a number of cell biological phenomena that require selectivity and specificity (1-3). One such phenomenon is selective "homing" of various types of lymphocytes in different parts of lymphoid organs that is dependent on lectinlike homing receptors $(4,5)$.

Homing is also involved in hemopoiesis, where hemopoietic progenitor cells selectively "home" to hemopoietic stroma, thus sustaining their proliferation and differentiation (6-9). Thus, after lethal irradiation and infusion of marrow cells in mice, the progenitor cells selectively seek and "home" in the stroma of spleen (10) and marrow (11). The conceptual frame of bone marrow transplantation in humans also rests on this selective "homing" $(12,13)$. Here, too, a source of hemopoietic stem cells is introduced in the general circulation in anticipation of their "homing" to the bone marrow stroma.

In recent years, the model of long-term marrow culture

Address reprint requests to Dr. Mehdi Tavassoli, Veterans Administration Medical Center (151), 1500 E. Woodrow Wilson Drive, Jackson, MS 39216. 1987.

Received for publication 17 April 1987 and in revised form 22 June

The Journal of Clinical Investigation, Inc.

Volume 80, December 1987, 1698-1705
(LTMC) ${ }^{1}$ has permitted in vitro reconstitution of interactions between the stroma and hemopoietic progenitor cells $(14,15)$. This model exploits the adherent capacity of stromal cells to various substrata. Such adherent stroma is then seeded with source progenitor cells which bind to the stromal cells. In this model, granulocyte-macrophage progenitor cells (CFU-C) proliferate and differentiate to form distinct foci on adherent stroma that appear as "cobblestones." Upon maturation, these cells are then released in the supernate (16). Without binding to the stroma, preexisting $\mathrm{CFU}-\mathrm{C}$ in marrow cell suspensions may undergo proliferation and differentiation to form colonies (e.g., in agar culture), but these processes are not sustained (17).

We have previously shown that in this model the homing of hemopoietic stem cell (CFU-S) is mediated by membrane lectins with galactosyl and mannosyl specificities (18). We now have extended these studies to determine the molecular basis whereby CFU-C is specifically recognized and bound to hemopoietic stroma cells and proliferates to form "cobblestones" on the surface of stroma. Using a series of neoglycoprotein probes recently synthesized in our laboratory (19), we attempted to inhibit the binding of CFU-C to the stromal cells. We now provide evidence that this binding is also mediated by a mechanism recognizing galactosyl and mannosyl residues and can be inhibited in the presence of galactosyl and mannosyl neoglycoprotein probes. In addition, suggestive evidence is presented that CFU-C surface membrane may contain lectins with these specificities.

\section{Methods}

Marrow cells. Male C57 black mice (10-12 wk old) were used. To obtain bone marrow cells, tibias and femurs were removed and cleaned from the surrounding tissues. The epiphyses were then removed and a needle was inserted into one end of the tubular bone and the marrow tissue was forced out in a test tube by a syringe containing Dulbecco's phosphate-buffered saline (PBS). Cell suspensions were made by agitating the tube, and cell concentration was adjusted to $10^{8}$ cells $/ 0.5 \mathrm{ml}$.

Synthesis of neoglycoprotein probes. The method for the synthesis of neoglycoprotein probes has been established in our laboratory and described in detail elsewhere (19). These probes are made by covalent binding of activated sugars in pyrannose form to a larger protein molecule such as bovine serum albumin (BSA). The method we developed for this purpose fulfills several theoretical requirements. (a) Binding of the sugar to a larger molecule prevents diffusion of small sugar molecules into the cells. (b) The sugar remains in pyrannose form that is

1. Abbreviations used in this paper: CFU-C, granulocyte-macrophage progenitor cell; CFU-S, hemopoietic stem cell; HEV, postcapillary venule; LTMC, long-term marrow culture; SEM, scanning electron microscope. 
necessary for binding to lectins or lectinlike substances. (c) The sugar/ protein ratio $(\sim 40: 50)$ is high enough to permit the use of neoglycoproteins as probes.

$L T M C$. This was done essentially as described before $(15,20)$. The marrow content of one long bone (femur or tibia) was flushed with a 21-gauge needle into a culture flask (T-25 Falcon 3013, Falcon Plastics, Cockeysville, MD) containing $8 \mathrm{ml}$ of Fisher medium (Gibco, Grand Island, NY) supplemented with $20 \%$ horse serum and $10^{-7} \mathrm{M}$ hydrocortisone. Cells were then gently pipetted several times to suspend them. Cultures were incubated at $33^{\circ}$ under $5 \% \mathrm{CO}_{2}$ in humidified air and the supernate was demidepopulated at weekly intervals. After $3 \mathrm{wk}$, when adherent cell colonies had developed into confluent state, all $8 \mathrm{ml}$ of the supernate were removed, and freshly harvested marrow cells were overlaid (recharged) at a concentration of $5 \times 10^{5}$ cells per $\mathrm{ml}$ (total of $8 \mathrm{ml}$ ) in the presence or absence of $10^{-3} \mathrm{M}$ concentration of neoglycoproteins (calculated on the basis of the sugar content of the preparation). This concentration of neoglycoproteins was selected because in differential agglutination studies, it was found capable of agglutinating the cells. Subsequent to recharging, the cultures were again demidepopulated at weekly intervals, and total cell count as well as concentration of CFU-C in the removed supernate were determined. Both data were adjusted to weekly production of cells and CFU-C. Cobblestones were also quantified and studied by scanning electron microscope (SEM). Upon termination LTMC, at 7 wk, the adherent layer was removed by teflon spatula and cell suspension was made. Cell count and CFU-C concentration were determined in this adherent layer.

Quantitation and morphology of cobblestones. Culture flasks were studied at weekly intervals (before the change of medium) by phase microscopy at low magnification. The entire surface of the culture flask was screened systematically and the number of cobblestones was scored. Cobblestone was defined as an accumulation of $>30$ small round cells bound to the stroma so that they could not be dislodged by tilting the flask. For SEM, several round 12-mm coverslips were placed in the flask. They were subsequently removed, fixed in modified Karnovsky fixative in cacodylate buffer (pH 7.2) for $2 \mathrm{~h}$ at $4^{\circ}$ and then postfixed in $1 \%$ similarly buffered $\mathrm{OsO}_{4}$ for $1 \mathrm{~h}$. The specimens were dehydrated in graded ethanol, critical point dried, coated with gold palladium, and studied.

$C F U-C$ assay. This assay determines the number of granulocytemacrophage progenitors by their clonal growth and differentiation into morphologically visible colonies. The method for their determination has been described (21). Briefly, $5 \times 10^{4}$ cells were incubated in $0.3 \%$ semisolid agar in alpha medium containing $20 \%$ horse serum. As a source of colony-stimulating activity (CSA), $20 \%$ medium conditioned with mouse peritoneal cavity macrophage (22) was incorporated into the semisolid agar. Agar cultures were maintained for $7 \mathrm{~d}$ at $37^{\circ} \mathrm{C}$ in $5 \% \mathrm{CO}_{2}$ in humidified air. Cultures were then examined under phase microscope, and colonies containing $>50$ cells were counted as CFU-C.

Differential agglutination technique. Differential cell agglutination was adapted from Inbar and Sachs with some modifications (23). Marrow cell suspensions $\left(10^{8}\right.$ cells $/ 0.5 \mathrm{ml}$ of PBS) were incubated in $0.7 \times 10 \mathrm{~cm}$ polystyrene tubes with the desired sugar-BSA (final concentration, $10^{-3} \mathrm{M}$ in PBS) for $60 \mathrm{~min}$ at $4^{\circ}$. In this method, those marrow cells that possess membrane receptors capable of binding specific sugars undergo agglutination. This leaves other cells in monodispersed form. The cells were then gently layered with a pasteur pipette on top of BSA solution ( $5 \% \mathrm{wt} / \mathrm{vol}$, total vol $7 \mathrm{ml}$ ) in a $15-\mathrm{ml}$ conical tube.

Preliminary experiments indicated that this layering with BSA was necessary to prevent sedimentation of nonagglutinated cells upon the subsequent centrifugation. Cells were then centrifuged for $2 \mathrm{~min}$ at 50 $g$. Unagglutinated cells remained at the top of BSA solution and this was called fraction 1. Most agglutinated cells formed large clumps (as examined by phase microscopy) that could not be easily disaggregated. These clumps sedimented to the bottom of the tube and were called fraction 3. Some cells also formed much smaller clumps that remained in the BSA layer. In contrast to fraction 3, these clumps could easily be disaggregated. This fraction was considered as fraction 2.

Cells in each fraction were collected and incubated for $10 \mathrm{~min}$ at $4^{\circ}$ with $0.2 \mathrm{M}$ of diffusible competing sugar solution in PBS to disperse the cells and obtain single cell suspensions again. The dispersed cells were collected by cytocentrifugation, washed thrice with PBS, counted in a hemocytometer, and representative samples were smeared and stained with Wright-Giemsa for differential counting. CFU-C concentration was then determined as discussed and the results were compared with controls using Student's $t$ test.

Preliminary experiments were also done omitting the centrifugation step and permitting sedimentation of agglutinated cells by gravity for $15 \mathrm{~min}$. It appeared that without centrifugation, sedimentation of agglutinated cells was incomplete and a brief centrifugation at low speed improved the sedimentation considerably. In addition, in some preliminary experiments, $0.168 \mathrm{M} \mathrm{NH}_{4} \mathrm{Cl}$ was initially used to remove the contaminant erythrocytes in the marrow cell suspensions. This manuever did not improve cell or CFU-C yield and was therefore abandoned.

\section{Results}

Cell and CFU-C production in LTMC. Fig. 1 shows cumulative cell production in these experiments. The number of cells at week zero reflects the number of cells in the medium before the addition of marrow. In control cultures, cumulative cell production continued almost as a linear function of time, as has been observed before $(14,16)$. However, in cultures containing $10^{-3} \mathrm{M}$ galactosyl or mannosyl probe cumulative cell production, which was higher than control during the first week, began to reach a plateau, indicating the cessation of cell production in the cultures. Cultures grown in the presence of fucosyl probe, all diffusible sugars, and BSA alone (in comparable concentrations) exhibited the pattern of control culture, indicating no effect on cell production.

A similar pattern was observed when CFU-C concentration was determined in these cultures (Fig. 2). In control cultures, cumulative CFU-C production rose linearly as a function of time. In the presence of $10^{-3} \mathrm{M}$ galactosyl and mannosyl probes, CFU-C production was halted $2 \mathrm{wk}$ after the initiation of cultures, so that the cumulative CFU-C production reached a plateau. Cultures grown in the presence of fucosyl probe, diffusible sugars, and BSA alone in comparable concentrations showed a pattern similar to that of control. At the termination of experiments, no CFU-C was found in the adherent layer in those flasks grown in the presence of galactosyl and mannosyl probes, but CFU-C was present in the adherent layer in control flasks $(18,810 \pm 710$ per flask $)$ and those grown in the presence of fucosyl probe or diffusible sugars.

Fig. 3 shows dose-response experiments for galactosyl probe. Complete inhibition was obtained at the concentration of $10^{-3} \mathrm{M}$, whereas no inhibition was obtained at the concentration of $10^{-5} \mathrm{M}$. Similar results were obtained for mannosyl probe.

Mixing experiments. To determine if galactosyl and mannosyl probes are synergistic in their effect to inhibit cell and CFU-C production, we carried out experiments in which the two probes were used in 1:1 ratio so that the molarity of the probes remained the same. There was no synergistic effect between the two probes as the magnitude of inhibition of total cell (Fig. $4 \mathrm{~A}$ ) and CFU-C production (Fig. $4 \mathrm{~B}$ ) in mixing experiments was similar to those for each probe alone. Simi- 

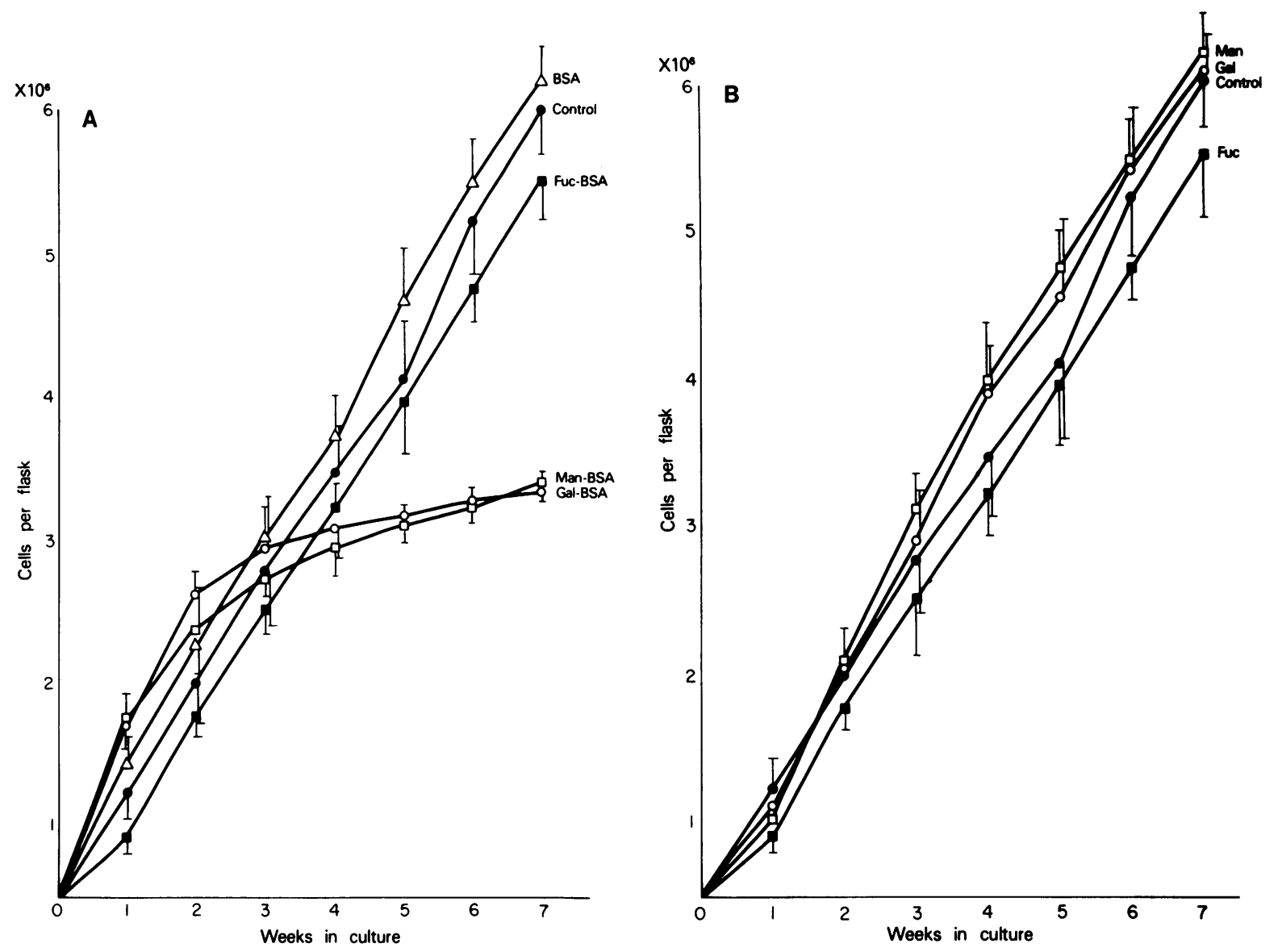

Figure 1. Cumulative cell production in the presence and absence of the three neoglycoprotein probes $(A)$ and diffusible sugars $(B)$. In the presence of galactosyl mannosyl probes, cell production ceases and cumulative cell production reaches a plateau. In control cultures and in the presence of fucosyl probe, BSA alone and the three diffusible sugars, cumulative cell production is a linear function of the time in culture.

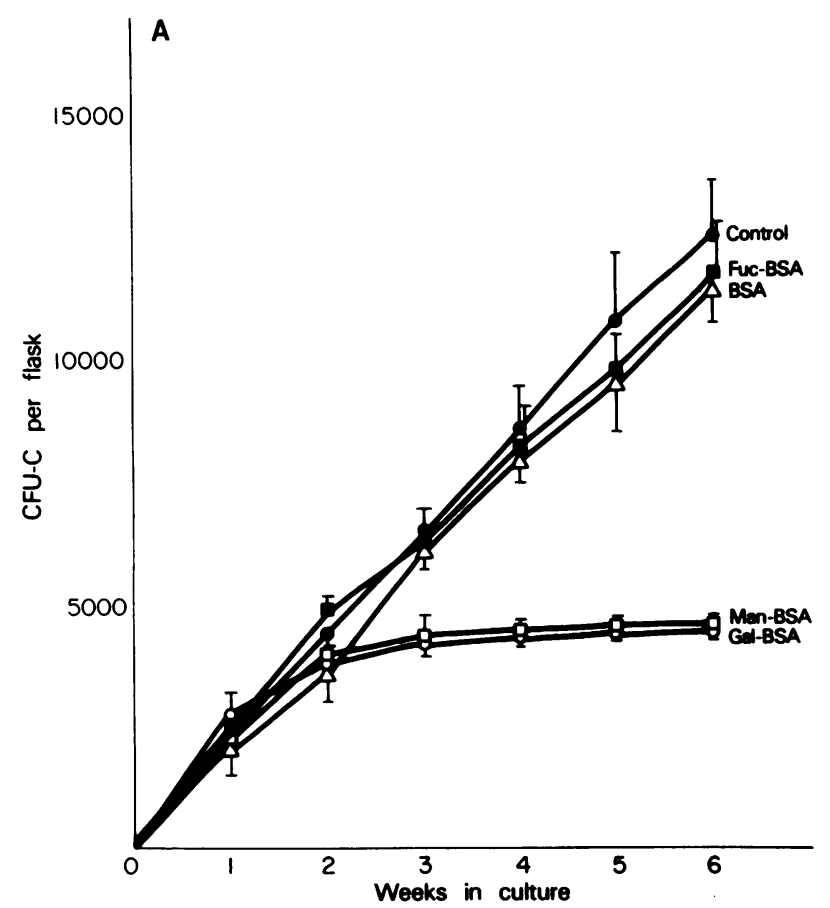

Figure 2. Cumulative CFU-C production in the presence and absence of the three neoglycoprotein probes, BSA alone, and the three diffusible sugars. In control cultures, cumulative CFU-C production is a linear function of the time in culture, whereas in the presence of

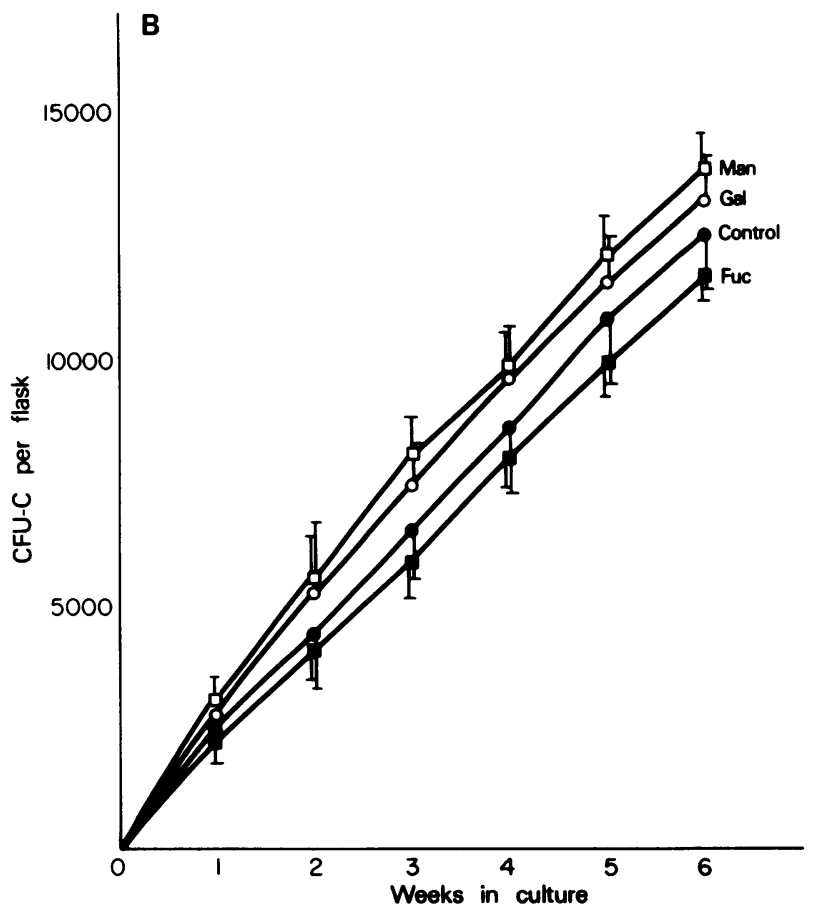

galactosyl and mannosyl probes, it reaches a plateau indicating CFU-C production in the cultures have halted. BSA alone, fucosyl probe, and diffusible sugars give a pattern similar to the control. 


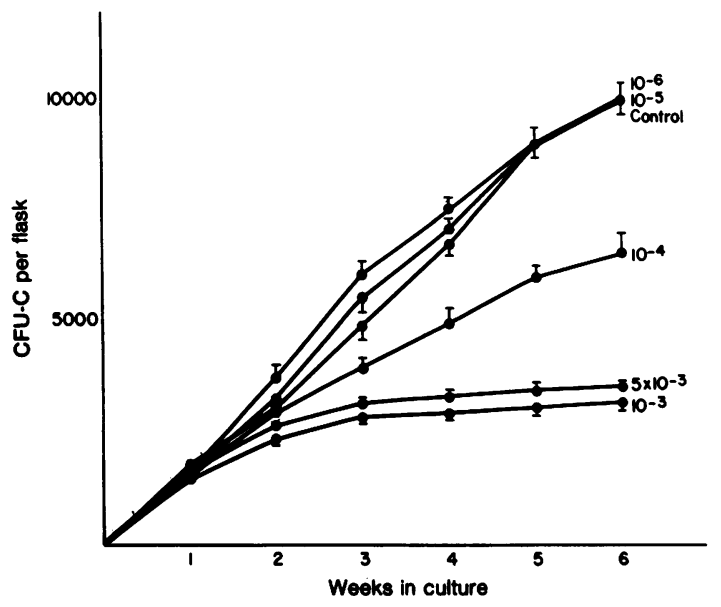

Figure 3. Cumulative CFU-C production in the presence of various dose of galactosyl probes. Molarity was calculated on the basis of the sugar content of the probe. Complete inhibition was obtained at the concentration of $10^{-3} \mathrm{M}$, whereas no inhibition was obtained at the concentration of $10^{-5} \mathrm{M}$.

larly, mixing experiments with the noninhibitory fucosyl probe and each of the two inhibitory probes showed inhibition of the magnitude comparable with that of inhibitory probes alone.

Quantitation and morphology of cobblestones. The number of cobblestones per flask (Fig. 5) decreased in normal cultures after the first week but, despite some variation, it stabilized after the second week and remained so for 6-8 wk. A similar pattern was also noted for cultures containing fucosyl probe. By contrast, in cultures containing galactosyl and mannosyl probes, the number of cobblestones was much lower in 1-wkold cultures and then approached zero and remained so. In these cultures only adherent stromal cells could be seen after 3 wk. Even the few cobblestones that were seen before $3 \mathrm{wk}$ appeared in phase microscopy to be much smaller and also less tightly bound to the stroma compared with control cultures as observed by the tilting of the flask. Fig. 6 shows the morphology of these cultures as seen by scanning electron microscopy (SEM).

In SEM, the stroma essentially consisted of two cell types (15). The first was spreading and forming a "floormat," with its branches spreading over the entire flask. The second cell type had round contour and many surface ridges, some of which appeared to be adherent to the flask surface. This cell type was considered to be macrophage (15). The cobblestones appeared as accumulation of $>30$ small round cells slightly heterogeneous in size $(9 \mu \mathrm{m})$ being adherent to the floormat cells (Fig. $6 \mathrm{~A}$ ). These cobblestones were frequent in control cultures and cultures grown in the presence of fucosyl probe, BSA alone, or diffusible sugars. Culture containing galactosyl and mannosyl probes were completely devoid of cobblestones and only the stromal adherent cells were seen (Fig. $6 B$ ).

Functional potential of probe-exposed CFU-C and stroma. To ensure that the exposure of probes did not alter the functional potential of CFU-C cultures were grown for $1 \mathrm{wk}$ in the presence of probes. The supernate (containing CFU-C) was then removed, washed free of probes, and grafted onto hemopoietic cell-free adherent layer. CFU-C production was then monitored weekly. CFU-C production continued (Fig. 7, Exp. 1) at a rate similar to control culture. To determine the functional potential of probe-exposed stroma, cultures were grown in the presence of probes for $5 \mathrm{wk}$, at which time total cell and CFU-C production was completely halted. At this time the supernate was removed and the adherent stromal layer was washed with medium and overlaid by stroma-free supernate (containing CFU-C). CFU-C production in these cultures was resumed at a rate comparable with control culture (Fig. 7, Exp. 2 ), indicating that the probe did not alter the potential of stroma for the support of CFU-C growth.

Differential agglutination of marrow cells. These studies suggested the presence of a sugar-lectin recognition system
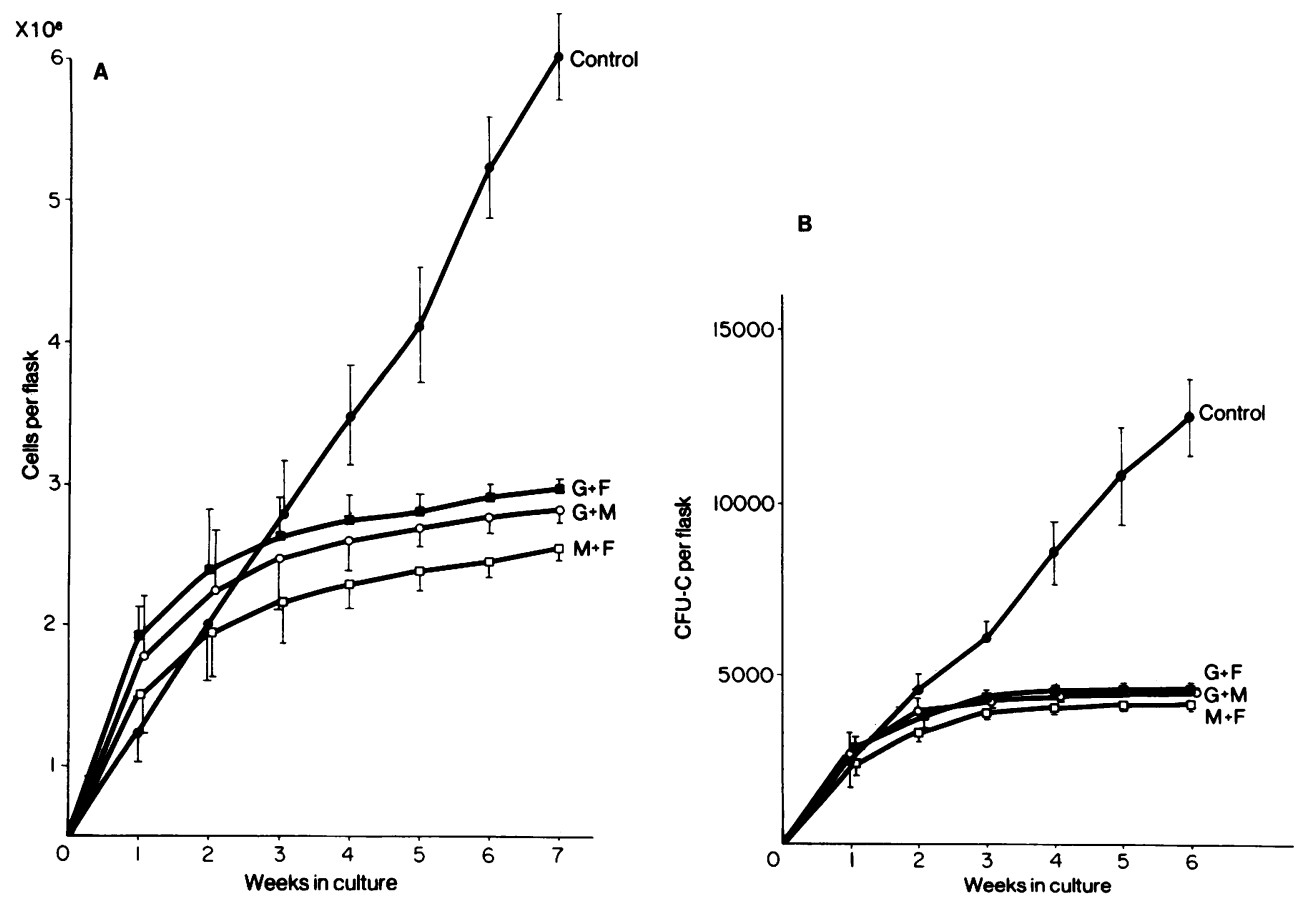

Figure 4. Mixing experiments. Cumulative total cell $(A)$ and CFU-C production $(B)$ in the presence of various combination of mannosyl $(M)$, galactosyl $(G)$, and fucosyl $(F)$ probes to a total concentration of $10^{-3} \mathrm{M}$. The method is described in the text. Magnitude of inhibition remains the same in all combinations indicating the absence of synergistic effect between mannosyl and galactosyl probes. 


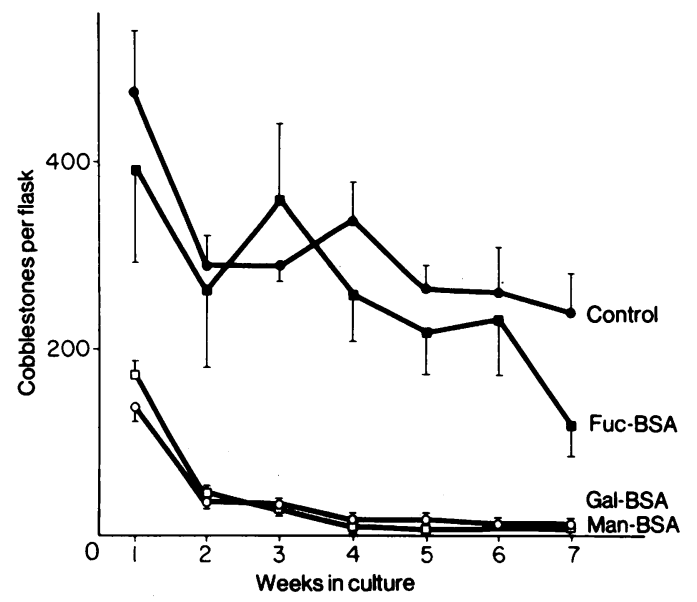

Figure 5. Quantitation of cobblestone areas in LTMC. In control cultures and in the presence of fucosyl probe, the number of cobblestones decreases during the first week and then reaches a plateau. In the presence of galactosyl and mannosyl probes, the number of cobblestone is much lower after 1 wk and then approaches zero.

with galactosyl and mannosyl specificities as the basis of homing of CFU-C to its supporting stroma. To determine whether CFU-C contains membrane lectins with these specificities, marrow cells were subjected to differential agglutination with all three neoglycoprotein probes as well as diffusible sugars. The recovery as percentage of total was $63.3,69.7$, and $64.4 \%$ in fraction 1, respectively, for galactosyl, mannosyl, and fucosyl probes. Corresponding figures for fraction 3 were 15.8, 22.7 , and $13.3 \%$. The remaining cells were found in fraction 2 . Fig. 8 shows the CFU-C concentrations in nonagglutinated and agglutinated fractions after differential agglutination.

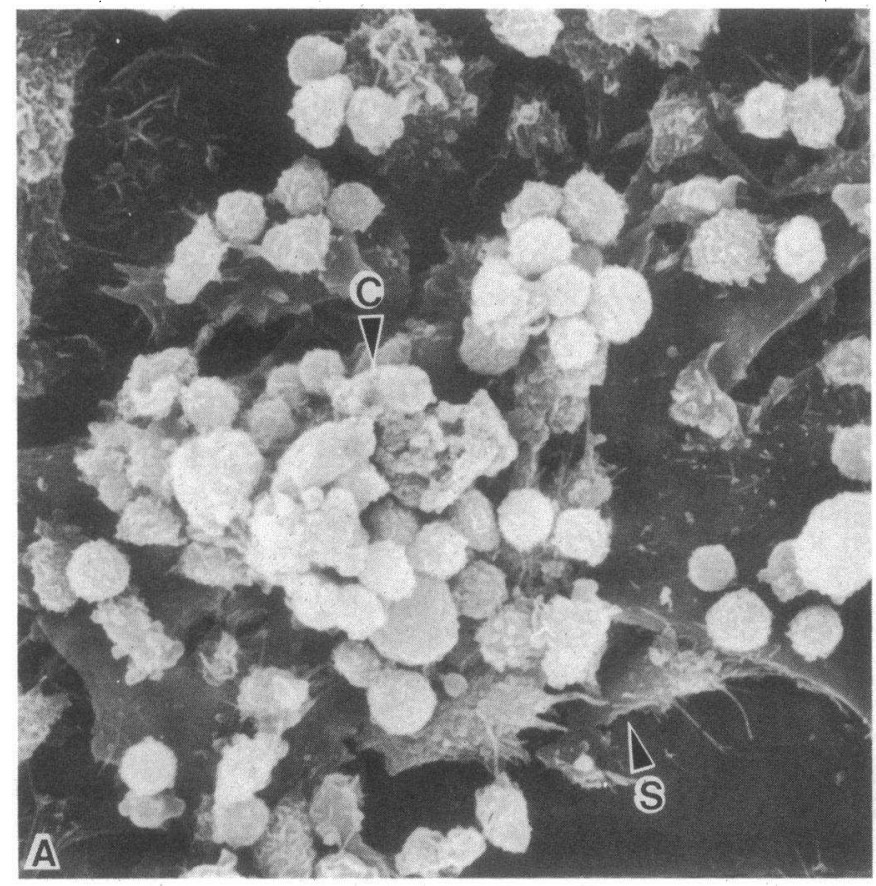

Figure 6. SEM of control culture $(A)$ demonstrating the binding of a group of round, small hemopoietic cells $(C)$ to the adherent, spreading stromal cells $(S)$ and partially covering the latter cells. This forms a cobblestone that could be recognized by phase microscopy. In cul-
Only galactosyl and mannosyl probes could differentially agglutinate CFU-C with enrichment factors of 1.97 and 2.15, respectively, in the agglutinated fraction. The results were statistically highly significant $(P<0.001)$. Most often agglutinated cells were more differentiated granulocytic cells which probably had retained their receptors in the course of maturation. Fucosyl-BSA, BSA alone, and diffusible sugars alone did not differentially agglutinate CFU-C, and the presence of CFU-C in fraction 3 reflected only the centrifugal force that was not differential.

\section{Discussion}

Hemopoiesis is the result of interaction between hemopoietic progenitor cells and the supporting stromal cells to which progenitor cells specifically bind (8). An experimental model that has been useful for the study of this interaction is long-term bone marrow culture (24). In this model CFU-C bind to adherent stromal cells (25). The binding is highly selective and specific (homing). Consequent to interactions between these cells and the stroma, proliferation, differentiation, and maturation of progenitor cells occur and mature cells are then released in the supernate. In this system, proliferating CFU-C is also released in the supernate, and in fact CFU-C in the supernate is in a state of equilibrium with those bound to the stroma. Proliferating and differentiating cells that are bound to the stroma form distinctive areas that can be visualized microscopically as cobblestones.

We have previously reported that the molecular basis of CFU-S homing to hemopoietic stroma relies on a recognition system with galactosyl and mannosyl specificities (18). In the present study we investigated the molecular basis whereby homing of CFU-C is mediated. The results provide strong evi-

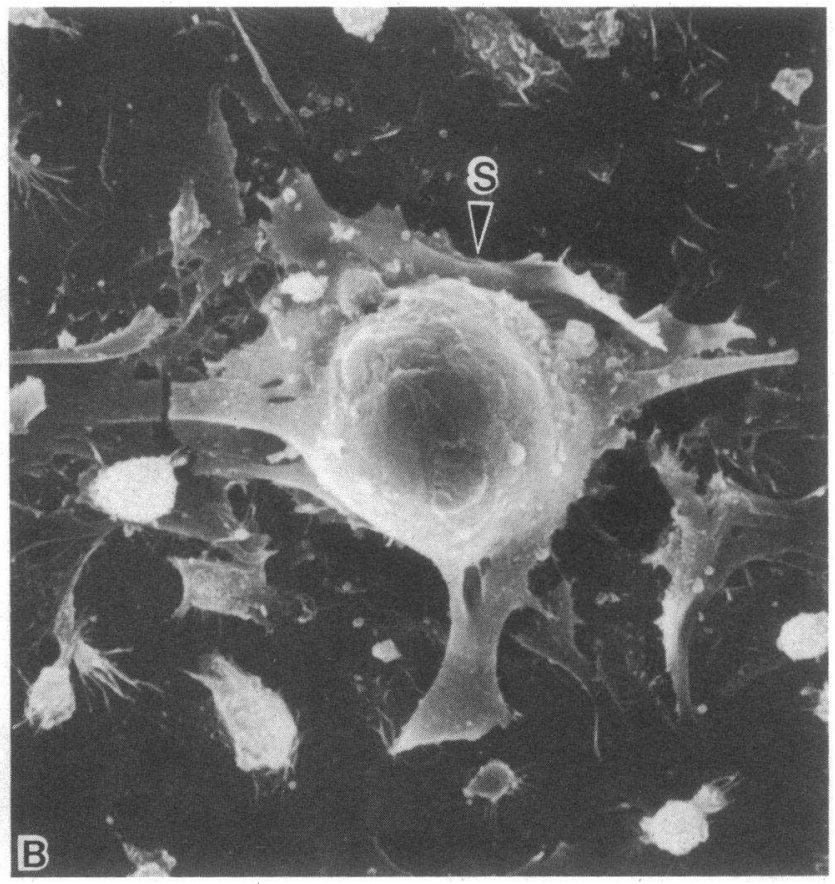

ture containing galactosyl $(B)$ and mannosyl probes, no cobblestones are seen and the adherent stromal cells is seen $(S)$ with its cytoplasmic branches spreading over the surface of the flask forming a "floormat." 4-wk cultures. $(A) \times 1,000 .(B) \times 1,000$. 


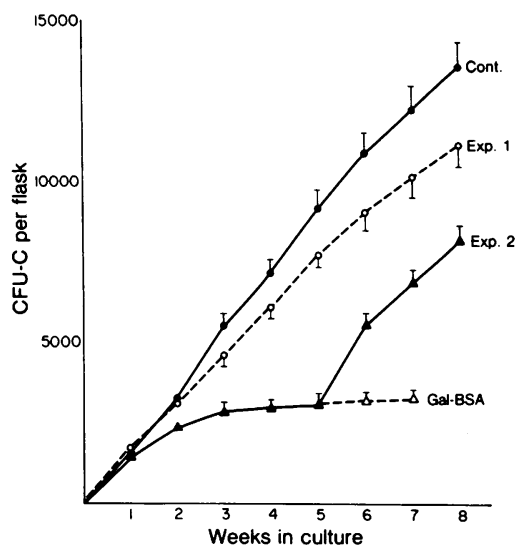

the probe, and supernate from control cultures was grafted onto In both experiments CFU-C production continues at a rate parallel to that of control culture, indicating no functional alteration upon exposure to the probe.

dence that it is also mediated by a recognition mechanism involving galactosyl and mannosyl residues. Thus, binding of progenitor cells to stromal cells and their subsequent proliferation and differentiation are inhibited in the presence of galactosyl and mannosyl probes in the culture medium. This inhibition is reflected in the halting of total cell and CFU-C production. Morphologically, too, cobblestones disappear in the presence of these sugar probes. This is also indicated by absence of CFU-C in the adherent layer upon termination of cultures, indicating that the absence of CFU-C in the supernate is not merely the result of different compartmentalization (stronger binding of cells to the stroma and lack of their release into the supernate).

That this halting is evident only after $2 \mathrm{wk}$ may reflect heterogeneity of CFU-C (26-28) and the presence in culture of a population of these cells far advanced in their differentiation state and no longer dependent on stromal binding. A similar

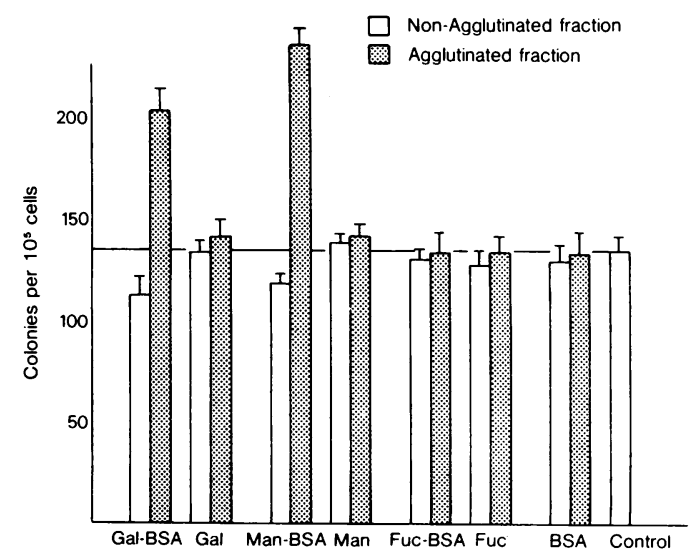

Figure 8. Marrow cells were incubated with neoglycoprotein probes, BSA alone, and diffusible sugars as discussed in the text. They were then layered over 5\% BSA solution (see experimental procedure) and centrifuged. CFU-C concentration was determined in fractions 1 (nonagglutinated) and 3 (agglutinated). Galactosyl and mannosyl probes differentially agglutinate CFU-C, whereas CFU-C concentration in the presence of fucosyl probe, BSA alone, and diffusible sugars remain comparable in the two fractions. Control is from fresh untreated marrow. situation is seen in the clonal analysis of CFU-C in agar, where proliferation and differentiation occur to form granulocytic colonies (17), but these processes are not sustained.

Because the sugar probes do not have direct cytotoxic effect (18) and do not alter the functional potential of CFU-C or stroma, our results indicate that the inhibition of total cell and CFU-C production must be at the level of binding of progenitor cells to stromal cells and that this binding is necessary for the subsequent proliferation and differentiation of progenitor cells.

The inhibitory effect of the two sugars on the homing of CFU-C is not synergistic and apparently both sugars are needed for homing because each of the probes can totally inhibit homing. This indicates that homing receptors must interact with a certain specific configuration of membrane glycoconjugates that involves both residues. Either progenitor cells or stromal cells may have membrane lectin-like substances (homing receptors) capable of specific recognition and binding of these two sugar residues with membrane glycoconjugates of the other cells. The studies on LTMC do not indicate whether these homing receptors are located on CFU-C or stromal cells. Thus, we carried out differential agglutination studies on CFU-C. These studies suggested the presence of homing receptors, interacting with galactosyl and mannosyl probes, on the surface of progenitor cells. However, the alternative possibility that stromal cells may also possess homing receptors can not be rules out, as these two possibilities are not mutually exclusive. That the enrichment factor hardly exceeds two may reflect the relatively low affinity of these receptors for their ligand. In a cloned hemopoietic progenitor cell, the dissociation constant $\left(K_{\mathrm{d}}\right)$ is in the range of $10^{-6} \mathrm{M}\left(3.11 \times 10^{-6} \mathrm{M}\right.$ for galactosyl and $6.88 \times 10^{-6} \mathrm{M}$ for mannosyl probes [18]), whereas for most receptors $K_{\mathrm{d}}$ is usually in the range of $10^{-9} \mathrm{M}$ or even higher. This low affinity is understandable in view of the fact that the association of hemopoietic cells with the stroma is a transient one and, upon maturation, they must become loose and enter the circulation. There is evidence in the literature that stronger binding of hemopoietic cells to stroma may inhibit their subsequent release and consequently lead to ineffective hemopoiesis (29-33).

Considerable attention has recently been focused on homing receptors in lymphocytes (4). These receptors are responsible for specific interaction of different subpopulations of lymphocytes with the high endothelium of the postcapillary venules (HEV) in lymphoid organs, an interaction that underlies the dynamic traffic of lymphocytes. It is of interest that homing receptors in lymphocytes are also lectins with specificity for mannosyl phosphate residues $(34,35)$. Moreover, lymphocyte homing receptors are associated with ubiquitin, thus forming a branched-chain protein with two $\mathrm{NH}_{2}$-termini $(4,36)$. Relative to lymphocytes, homing receptors of hemopoietic progenitor cells have not been studied. This may be in part the result of technical difficulties in obtaining purified preparations of hemopoietic progenitor cells. Whereas many subpopulations of lymphocytes can now be isolated with the use of monoclonal antibodies, assays for hemopoietic progenitor cells are still crude bioassays.

Differences exist between lymphocyte homing in lymphoid organs and CFU-C homing in the present system. Binding of lymphocytes to HEV is followed by engulfment of lymphocyte by $\mathrm{HEV}$ in a similar manner that soluble ligands are internalized (37-41). Lymphocytes are subsequently externalized to 
the abluminal side (42). CFU-C binding to the stroma is not followed by internalization, and it is possible that the binding may alter the configuration of receptors or membrane glycoconjugates so that CFU-C and its progeny are fixed to the stromal cells preventing internalization. In fact, it is entirely possible that this putative alteration in the configuration of the molecules may be instrumental in initiating the processes of proliferation or differentiation or the susceptibility of the cell to stimulators of these processes. The relation of homing to proliferation and differentiation of the cell requires further studies. It is also to be noted that the binding of CFU-C to the stromal cells must be a temporary phenomenon, because upon maturation the cells are released into the supernate.

Nonetheless, certain parallelism exists between homing of lymphocytes and CFU-C. In both systems, homing receptors appear to be lectins with defined specificities for sugar residues of membrane glycoconjugates.

It is entirely possible that this homing mechanism is also involved in vivo. Binding of granulocytic progenitor cells to specific type of alkaline phosphatase-positive stromal reticular cell has been reported in bone marrow (43), and these cells both morphologically and cytochemically resemble LTMC stromal cells to which progenitor cells bind to form cobblestones. In this context, it should be mentioned that in vivo homing of hemopoietic progenitor cells, such as may occur in the case of bone marrow transplantation, appears to be somewhat more complicated, because it might involve a two-step phenomenon. Progenitor cells must first be recognized by marrow endothelium and transported to the extravascular (hemopoietic) space where homing to specific stromal cells occurs. It is possible that the specific recognition of these cells by marrow endothelium also involves a similar mechanism. In this context, it is of interest that receptors with defined specificity for galactosyl residues of glycoconjugates have been identified on the luminal surface of marrow endothelium (44).

\section{Acknowledgments}

This work was supported by National Institutes of Health grant No. DK-30142.

\section{References}

1. Greig, R. G., and M. N. Jones. 1977. Mechanisms of intercellular adhesion. Biosystems. 9:43-55.

2. Sharon, N., and H. Lis. 1982. Glycoproteins: research booming on long ignored ubiquitous compounds. Mol. Cell. Biochem. 42:167187.

3. Vayss, J., L. Gattegno, D. Bladier, and D. Aminoff. 1986. Adhesion and erythrophagocytosis of human senescent erythrocytes by autologous monocytes and their inhibition by $\alpha$-galactosyl derivatives. Proc. Natl. Acad. Sci. USA. 83:1339-1343.

4. Gallatin, M., T. P. St. John, M. Siegelman, R. Reichert, E. C. Butcher, and E. L. Weissman. 1986. Lymphocyte homing receptors. Cell. 44:673-680.

5. Hooghe, R. J., and J. R. L. Pink. 1985. The role of carbohydrate in lymphoid cell traffic. Immunol. Today. 6:180-181.

6. McCulloch, E. A., L. Siminovitch, J. E. Till, E. S. Russell, and S. E. Bernstein. 1965. The cellular basis of the genetically determined hemopoietic defect in anemic mice of genotype S1/S1d. Blood. 26:399-410.

7. Tavassoli, M. 1975. Studies on hemopoietic microenvironments. Exp. Hematol. (NY). 3:213-216.
8. Tavassoli, M., and W. H. Crosby. 1968. Transplantation of marrow to extramedullary sites. Science (Wash. DC). 161:54-56.

9. Wolf, N. S., and J. J. Trentin. 1968. Hemopoietic colony studies. V. Effect of hemopoietic organ stroma on differentiation of pluripotent stem cells. J. Exp. Med. 127:205-214.

10. Till, J. E., and E. A. McCulloch. 1961. A direct measurement of the radiation sensitivity of normal mouse bone marrow cells. Radiat. Res. 14:213-222.

11. Tavassoli, M. 1979. The marrow-blood barrier. Br. J. Haematol. 41:297-302.

12. Thomas, E. D. 1976. Progress in marrow transplantation. $J$. Am. Med. Assoc. 235:611-612.

13. Robertson, M. 1979. Bone-marrow transplantation: man and mouse. Nature (Lond.). 280:720-721.

14. Dexter, T. M., and L. G. Lajtha. 1974. Proliferation of haemopoietic stem cells in vitro. Br. J. Haematol. 28:525-530.

15. Tavassoli, M., and K. Takahashi. 1982. Morphological studies on long-term culture of marrow cells: characterization of the adherent stromal cells and their interactions in maintaining the proliferation of hemopoietic stem cells. Am. J. Anat. 164:91-111.

16. Dexter, T. M., T. D. Allen, and L. G. Lajtha. 1974. Conditions controlling the proliferation of haemopoietic stem cells in vitro. J. Cell. Physiol. 91:335-344.

17. Bradley, T. R., and D. Metcalf. 1966. The growth of mouse bone marrow cells in vitro. Aust. J. Exp. Biol. Med. Sci. 44:287-299.

18. Aizawa, S., and M. Tavassoli. 1987. In vitro homing of hemopoietic stem cells is mediated by a recognition system with galactosyl and mannosyl specificities. Proc. Natl. Acad. Sci. USA. 84:4485-4489.

19. Kataoka, M., and M. Tavassoli. 1984. Synthetic neoglycoproteins: a class of reagents for detection of sugar-recognizing substances. J. Histochem. Cytochem. 32:1091-1098.

20. Tavassoli, M. 1984. Radiosensitivity of stromal cells responsible for in vitro maintenance of hemopoietic stem cells in continuous, long-term marrow culture. Exp. Hematol. (NY). 10:435-443.

21. Aizawa, S., and M. Tavassoli. 1986. Expression of lectin receptors on the surface of granulocyte-macrophage progenitor cells (CFUgm). Int. J. Cell Cloning. 4:464-471.

22. Horiuchi, M., and Y. Ichikawa. 1977. Control of macrophage and granulocyte colony formation by two different factors. Exp. Cell Res. 110:79-85.

23. Inbar, M., and L. Sachs. 1969. Structural differences in sites on the surface membrane of normal and transformed cells. Nature (Lond.). 223:710-712.

24. Dexter, T. M., and N. G. Testa. 1980. In vitro methods in haemopoiesis and lymphoiesis. J. Immunol. Methods. 38:177-190.

25. Dexter, T. M., T. D. Allen, L. G. Lajtha, F. Krizsa, N. G. Testa, and M. A. Moore. 1978. In vitro analysis of self renewal and commitment of hematopoietic stem cells. In Differentiation of Normal and Neoplastic Hematopoietic Cells. B. Clarkson, M. Marks, and J. Till, editors. Cold Spring Harbor Laboratories, Cold Spring Harbor, NY. 63-80.

26. Metcalf, D., and H. R. McDonald. 1975. Heterogeneity of in vitro colony and cluster forming cells in the mouse marrow: segregation by velocity sedimentation. J. Cell. Physiol. 85:643-650.

27. Williams, N., and G. J. Van Den Engh. 1975. Separation of subpopulations of in vitro colony forming cells from mouse bone marrow by equilibrium density centrifugation. J. Cell. Physiol. 86:237-249.

28. Bol, S., and N. Williams. 1980. The maturation of three types of granulocyte/macrophage progenitor cells from mouse bone marrow. $J$. Cell. Physiol. 102:233-243.

29. Breton-Gorius, J., G. Flandrin, M. T. Daniel, and J. C. Brouet. 1973. Septate-like junctions acquired by erythroblasts in a case of refractory anemia. Scand. J. Haematol. 10:219-224.

30. Lewis, S. M., and R. L. Verwilghen. 1973. Dyserythropoiesis and dyserythropoietic anemias. Prog. Hematol. 8:99-129.

31. Tavassoli, M., and M. Shaklai. 1979. Junctional structures in 
haemopoiesis: a study of bone marrow using freeze-fracture and lanthanum impregnation techniques. Br. J. Haematol. 43:235-241.

32. Sanel, F. T., and A. A. Serpick. 1970. Plasmalemmal and subsurface complexes in human leukemic cells: membrane bonding by zipperlike junctions. Science (Wash. DC). 168:1458-1460.

33. Blom, J. 1977. The ultrastructure of macrophage found in contact with plasma cells in the bone marrow of patients with multiple myeloma. Acta Pathol. Microbiol. Scand. Sect. A Pathol. 85:335-344.

34. Stoolman, L. M., and S. D. Rosen. 1983. Possible role for cell-surface carbohydrate-binding molecules in lymphocyte recirculation. J. Cell Biol. 96:722-729.

35. Stoolman, L. M., T. S. Tenforde, and S. D. Rosen. 1984. Phosphomannosyl receptors may participate in the adhesive interaction between lymphocytes and high endothelial venules. J. Cell Biol. 99:1535-1540.

36. Siegelman, M., M. W. Bond, W. M. Gallatin, T. St. John, H. T. Smith, V. A. Fried, and I. L. Weissman. 1986. Cell surface-molecule associated with lymphocyte homing is a ubiquitinated branched-chain glycoprotein. Science (Wash. DC). 231:823-829.

37. Cho, Y., and P. P. H. DeBruyn. 1979. The endothelial structure of the postcapillary venules of the lymph node and the passage of lymphocytes across the venule wall. J. Ultrastruct. Res. 69:13-21.
38. Tavassoli, M., T. Kishimoto, M. Kataoka, R. Soda, and K. Harjes. 1986. Liver endothelium mediates the uptake of iron-transferrin complex by hepatocytes. Exp. Cell Res. 165:369-379.

39. Soda, R., and M. Tavassoli. 1984. Transendothelial transport of iron-transferrin complex in the bone marrow. J. Ultrastruct. Res. 88:18-29.

40. Kataoka, M., and M. Tavassoli. 1985. The role of liver endothelium in the binding and uptake of ceruloplasmin: studies with colloidal gold probe. J. Ultrastruct. Res. 90:194-202.

41. Kishimoto, T., and M. Tavassoli. 1987. Transendothelial transport (transcytosis) of iron-transferrin complex in the liver. Am. J. Anat. 178:241-249.

42. Farr, A. G., Y. Cho, and P. P. H. DeBruyn. 1980. The structure of the sinus wall of the lymph node relative to its endocytic properties and transmural cell passage. Am. J. Anat. 157:265-284.

43. Westen, H., and D. F. Bainton. 1979. Associated of alkalinephosphatase-positive reticulum cells in bone marrow with granulocytic precursors. J. Exp. Med. 150:919-937.

44. Kataoka, M., and M. Tavassoli. 1985. Identification of lectinlike substances recognizing galactosyl residues of glycoconjugates on the plasma membrane of marrow sinus endothelium. Blood. 65:11631171. 